Article

\title{
Dental Treatment of White Spots and a Description of the Technique and Digital Quantification of the Loss of Enamel Volume
}

\author{
Ana Roig-Vanaclocha, María Fernanda Solá-Ruiz * (), Juan Luis Román-Rodríguez, \\ José Amengual-Lorenzo, Jorge Alonso Pérez-Barquero and Rubén Agustín-Panadero $D$ \\ Department of Stomatology, Faculty of Medicine and Dentistry, University of Valencia, 46010 Valencia, Spain; \\ aroigva@hotmail.com (A.R.-V.); juanluis.romanrodriguez@gmail.com (J.L.R.-R.); \\ ppamengual@gmail.com (J.A.-L.); jorgealonso86@gmail.com (J.A.P.-B.); ruben.agustin@uv.es (R.A.-P.) \\ * Correspondence: m.fernanda.sola@uv.es
}

Received: 17 May 2020; Accepted: 22 June 2020; Published: 25 June 2020

\begin{abstract}
The prevalence of white spots on teeth has increased in recent years. Regardless of their etiology, these lesions are characterized by a reduction in the enamel's mineral phase, which is replaced by organic fluids. This causes an alteration of its chemical composition that affects its optical characteristics. Subsurface demineralization increases the pore volume of enamel, which in turn changes its optical refraction and results in the opaque color of white spot lesions. Here, we examined a non-invasive clinical technique used for eliminating these white spot lesions from enamel via two $\mathrm{HCl}$-based products at different concentrations (6.6\% and $15 \%)$. We used a digital method for evaluating the volumetric changes produced in dental enamel by the application of both products, one of which involved chemical erosion and the other, abrasive erosion. The mean volume of the enamel eliminated was $-0.042 \mathrm{~mm}$ in $15 \% \mathrm{HCl}$, and $-0.12 \mathrm{~mm}$ in $6.6 \% \mathrm{HCl}$. Thus, both $15 \% \mathrm{HCl}$ and $6.6 \% \mathrm{HCl}$ are capable of eroding the surface of the tooth enamel without reaching dentin. Moreover, $6.6 \% \mathrm{HCl}$ produced a greater erosion of the dental enamel and left the surface a texture typical of an abrasive chemical-erosive product. The $15 \% \mathrm{HCl}$, however, produced an etching pattern typical of an erosive chemical with open enamel prisms prepared for subsequent adhesive procedures and restorers.
\end{abstract}

Keywords: white spots; hydrochloric acid; ICON Etch; chemical erosion; abrasive erosion

\section{Introduction}

Dental enamel is a highly mineralized acellular connective tissue formed by specialized cells known as ameloblasts. It is composed largely of hydroxyapatite (98\%), with some organic components and water (2\%) [1]. Developmental defects in enamel may be due to genetic mutations [2], environmental alterations, infection, medication, radiation, or trauma [3,4]. When the composition of dental enamel undergoes a reduction in hydroxyapatite, an increase in organic components that cause dental discoloration appear, which are commonly known as 'white spots' [5]. These are characterized by an intact exterior surface and a deeper demineralized area [6]. The spots are perceived by the human eye as opaque white-colored lesions due to refraction of the light that falls on the demineralized areas that have a refractive index $(\mathrm{RI})$ lower than that of healthy enamel $(\mathrm{RI}=1.62-1.65)$, similar to air or water $(\mathrm{RI}=1.00-1.33)[7]$.

Enamel defects occur as a result of damage occurring either before or after an eruption in the affected tooth $[8,9]$. Pre-eruptive lesions are considered to derive from dental fluorosis, dental treatments, or from cases of molar incisor hypomineralization (MIH) $[5,10,11]$. Post-eruptive lesions, also known as white spot lesions (WSLs), are white spots that appear after orthodontic treatment. 
The prevalence of these spots is $24 \%$, or anywhere between $50 \%$ and $97 \%$ following treatment with orthodontic multibrackets and multibands, which mainly affect the gingival third of the vestibular faces of the maxillary incisors [12-15].

Various techniques have been established to improve the esthetics of these enamel surface lesions [16]. In recent years, tooth whitening has become a widely used technique as it is safe, economically feasible, and minimally invasive. It eliminates internal and external discolorations from teeth and camouflages white spots on the surface by increasing the general luminosity of the affected tooth $[17,18]$. Another option is remineralization with fluoride or casein phosphopeptide, which can also produce good results when restoring the surface layers of caries lesions. However, clinical trials have not reported any cosmetic improvements, since the white spots tend to persist long term $[19,20]$. It is also considered to be a rather unpredictable treatment that requires prompt application and patient collaboration [21-24]. Lastly, microabrasion with $6.6 \%$ hydrochloric acid $(\mathrm{HCl})$-based products is an effective treatment for white spots that involves the removal of the affected adamantine tissue [16,25-32]. Erosion using 15\% HCl-based products and subsequent infiltration of the intercrystalline spaces with low viscosity resin without milling the affected surface is a minimally invasive treatment that camouflages white spots, since the infiltration resin has a similar refractive index (I.R: 1.52) to hydroxyapatite. The refraction of light falling on the resin makes the human eye perceive the tooth color as unaltered in white spot areas [33-37]. As the HCl-based products used in this technique work through the erosion of the enamel, the site of application to the tooth's vestibular surface should be considered carefully in relation to the product's erosive capacity. In this context, Atsu et al. [38] found that in the crown's middle third, within an interval of 3-5 mm from the cemento-enamel junction, the enamel has a thickness of $0.54-0.75 \mathrm{~mm}$ to the dentin.

According to the manufacturer's instructions, the etching time for $15 \% \mathrm{HCl}$ is two minutes. If the white spots persist, etching can be repeated twice more, making a total etching time of six minutes; however, repeated etching on the enamel surface will cause a greater breakdown of enamel prisms. For this reason, it is important to quantify the capacity for eliminating the products used and ensure that they do not reach the dentin-enamel interface in order to avoid problems derived from $\mathrm{HCl}$ infiltration into the dentin tubules. In cases of severe enamel discoloration, treatments generally tend to involve more invasive methods, such as resin composite restoration, ceramic veneers, or even crowns; this will provide excellent esthetic results but will involve an extensive loss of dental tissue, which weakens the tooth's mechanical properties [39,40].

All of the available treatments deal with white spots adequately, and each has well defined indications. For this reason, the least invasive and least costly should be an ethical priority for dentists when selecting treatment types for their patients [40].

The objective of this study was to describe a non-invasive clinical technique that eliminates white spots from enamel using $\mathrm{HCl}$-based products at different concentrations $(6.6 \%$ and $15 \%)$ as variations in acid concentration. Additionally, the mode of application determines the extent of volumetric change on the enamel surface. Along with describing the clinical protocol, the outcomes from this study were analyzed through in vitro digital quantification of the loss of enamel volume.

\section{Materials and Methods}

\subsection{Description of the Clinical Process to Remove White Spots Located in the Enamel}

To begin, a clinical protocol was followed to treat white spots using one of two commercially available $\mathrm{HCl}$-based products that involved either a chemical erosion technique or an abrasive erosion technique.

Secondly, an intraoral scanner was used to generate Standard Tessellation Language (STL) files using specialized software to quantify the enamel loss produced with each technique. Then, the following steps were followed in sequence: 
1. Isolation of the operative field using anchorage clamps in the posterior regions and ligatures in the anterior regions to ensure unvarying isolation during treatment.

2. Initial scan of affected teeth from which an STL file was generated. Scans were taken before and after different treatment applications to evaluate the quantity of tissue eliminated.

3. Application of the $\mathrm{HCl}$-based product to white spots:

3.1. In cases where the $15 \% \mathrm{HCl}$ product was applied (ICON etch; DMG), each affected tooth received three applications of chemical erosion treatment for two minutes each. The product was placed with the tip of a sponge applicator on the enamel surface for $2 \mathrm{~min}$. When $2 \mathrm{~min}$ had passed, the enamel was washed with abundant water for $30 \mathrm{~s}$ (Figures 1,3 and 5).

3.2. In this study, the abrasive erosion treatment (Opalustre; Ultradent) contained a $6.6 \%$ $\mathrm{HCl}$ slurry with silicon carbide microparticles; this combination offered a chemical stain removal along with gentle mechanical abrasion. In cases using $6.6 \% \mathrm{HCl}$, teeth with white spots were treated with various applications according to the manufacturer's instructions. The product was spread on the enamel surface in a $1 \mathrm{~mm}$ thick uniform layer. Afterwards, it was rubbed homogeneously for $1 \mathrm{~min}$ using Opal Cups (Ultradent) provided by the manufacturer. The enamel was then washed in abundant water for $30 \mathrm{~s}$ (Figures 2, 4 and 6).

4. Affected teeth were then scanned with an intraoral scanner (TrueDefinition, 3M-ESPE) and the data were used to generate STL files.

5. Volumetric change was analyzed by means of superimposing the STL files obtained from the scans. The STL files were imported to use the reverse engineering software Geomagic Wrap (3D system), which aligns the data in each file using the best fit algorithm. To do this, the initial file reference mesh was selected, and subsequent meshes were aligned over it as independent floating meshes. For the alignment process, the vestibular area of the teeth presenting variations from one scan to another was omitted due to $\mathrm{HCl}$ application.

6. After the final alignment, each tooth was exported in a binary STL format to a program called GOM Inspect (Precise Industrial 3D Metrology). This program generates a gradient color map representing variations from $250 \mu \mathrm{m}$ to $-250 \mu \mathrm{m}$ so that any point exhibiting a difference between the initial mesh and the succession of the $\mathrm{HCl}$ application is represented by a specific color.

7. After quantifying the volume of eliminated enamel, the data were processed to calculate the depth affected by the treatment within the enamel layer. In this way, the dentist was able to know whether to continue applying $\mathrm{HCl}$, to terminate treatment, or to carry out more invasive treatment.

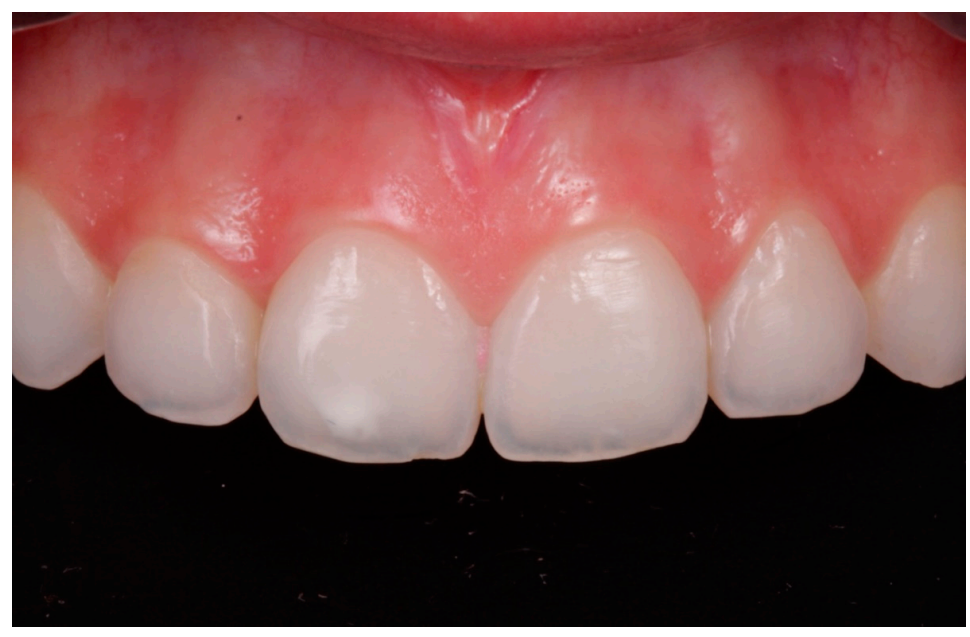

Figure 1. The initial situation of a white spot from a traumatic etiology. 


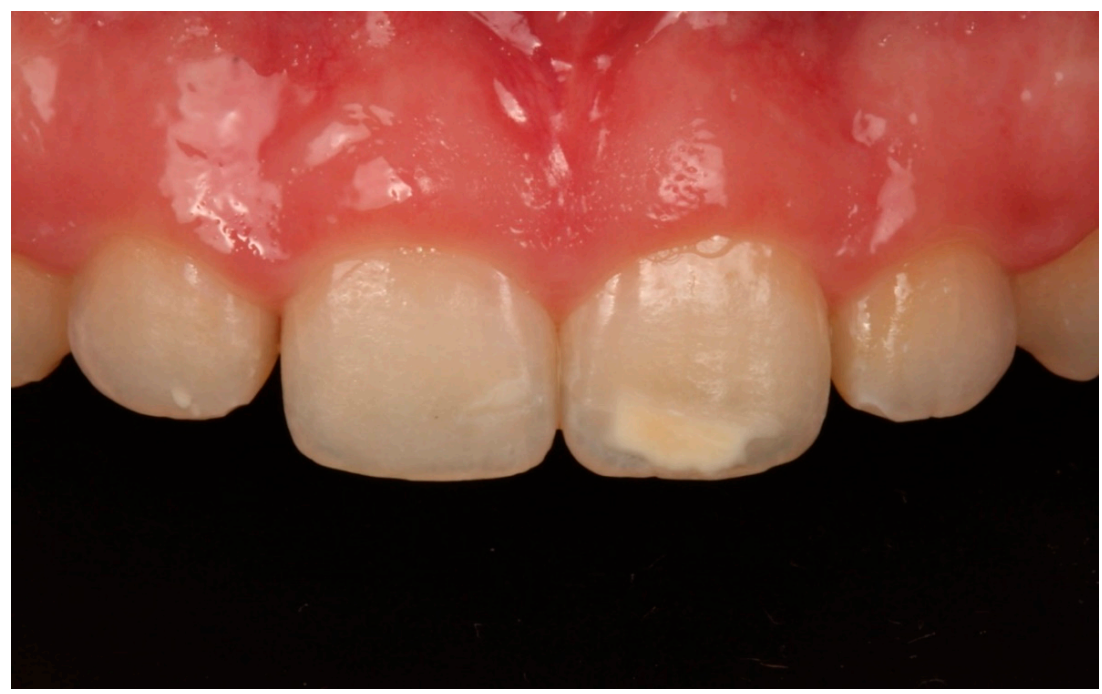

Figure 2. The initial situation of a molar incisor hypomineralisation (MIH) white spot.

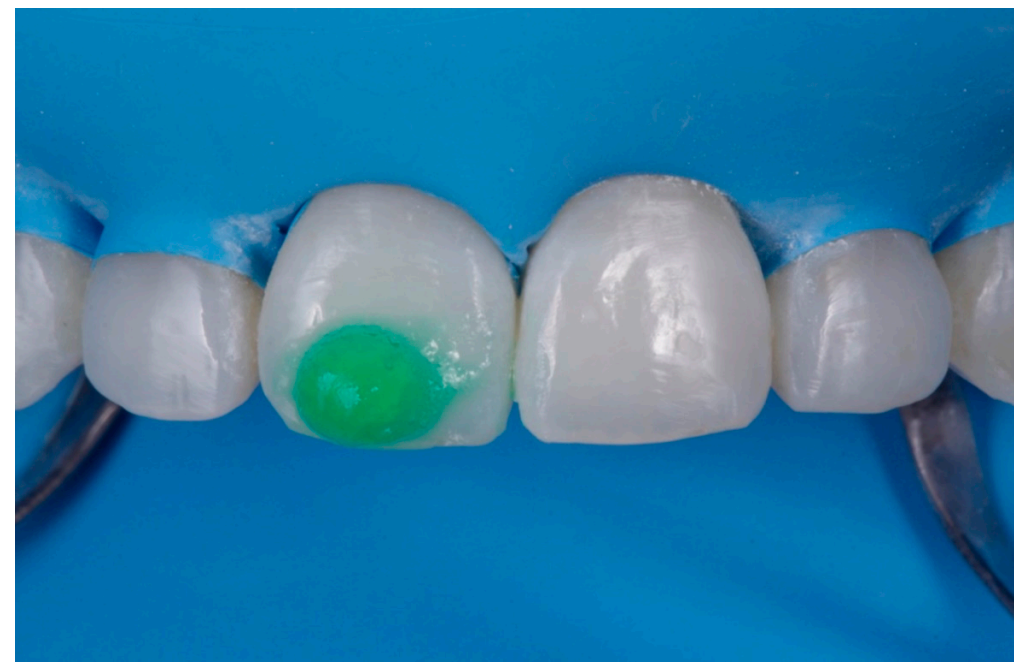

Figure 3. The treatment of the same white spot with $15 \%$ hydrochloric acid ( $\mathrm{HCl})$ (ICON etch).

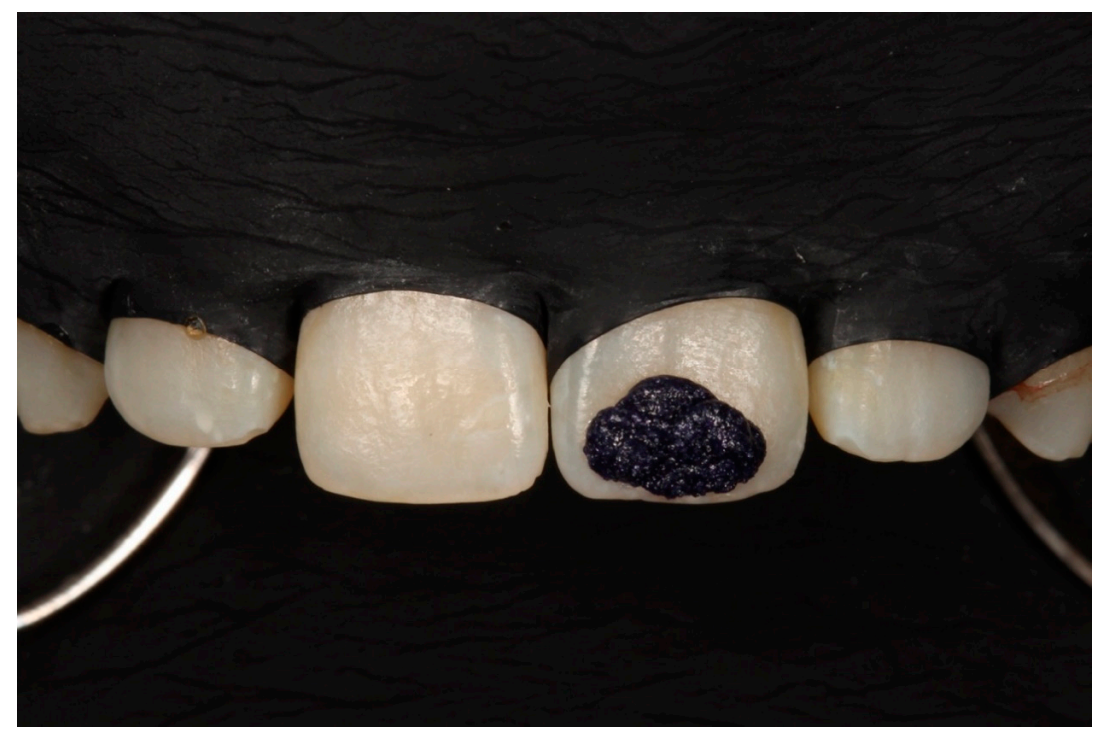

Figure 4. The treatment of the same white spot with $6.6 \% \mathrm{HCl}$ (Opalustre). 


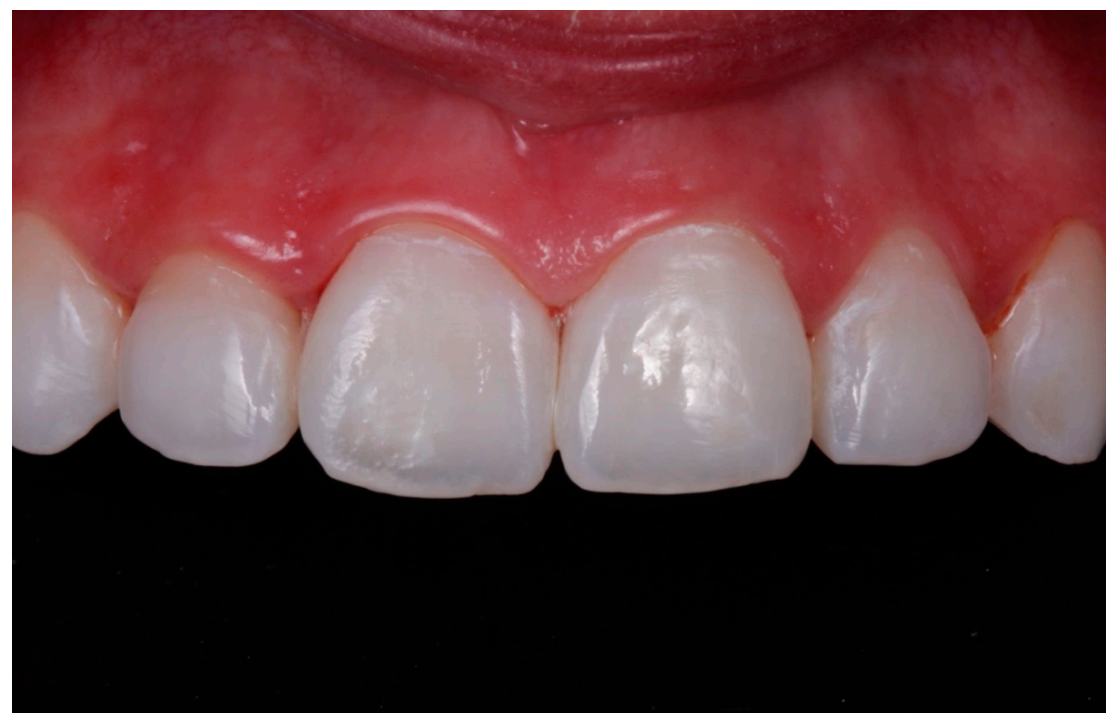

Figure 5. The situation after camouflaging the white spot with an application of $15 \% \mathrm{HCl}$.

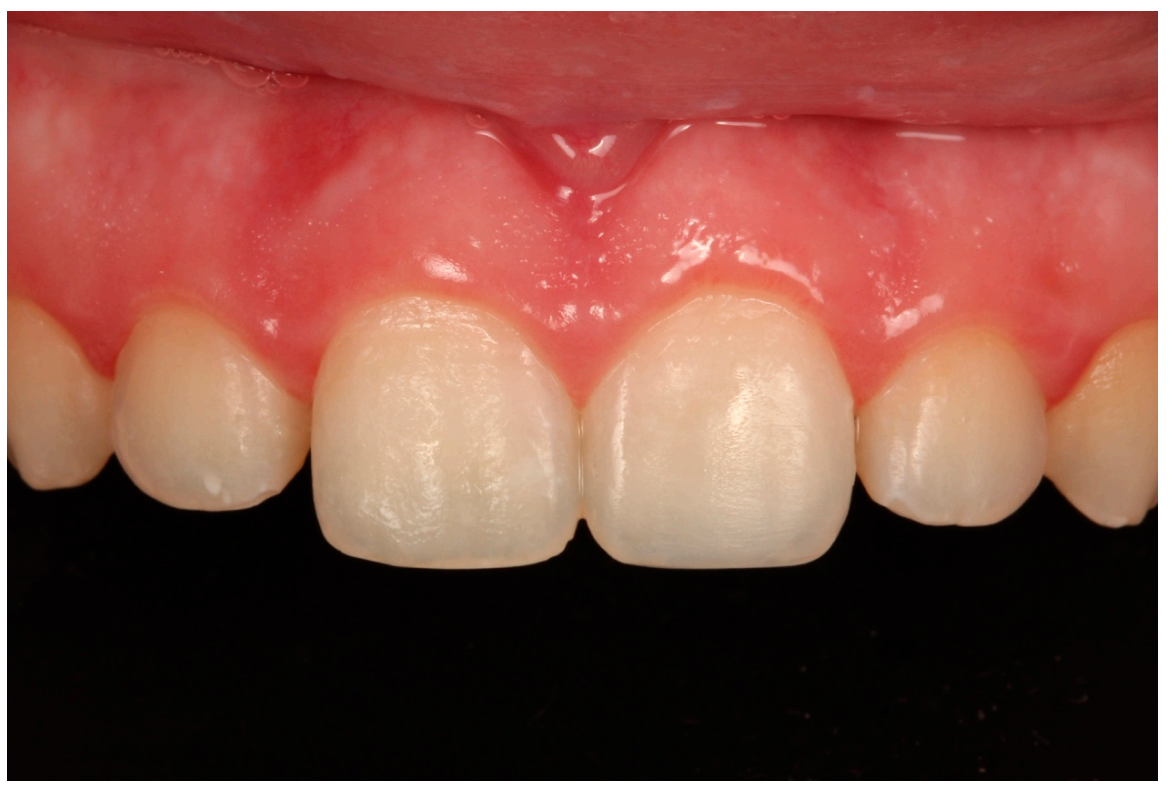

Figure 6. The situation after the removal of the white spot with the application of $6.6 \% \mathrm{HCl}$.

\subsection{In Vitro Volumetric Study of Application of HCl-Based Agents}

The digital quantification method described above will help dentists avoid the clinical complications that complete enamel loss can cause, as well as the subsequent restoration to overcome them. An in vitro pilot study was performed to show that it is possible to manage enamel loss objectively by using the superimposing STL files method. Type IV dental plaster models were fabricated following the protocol adopted in previous studies to support two extracted natural human central incisors without white spot lesions [41,42], as white spots show higher prevalence in the central incisors (between 8.3 and 51.6\%) $[43,44]$. Several previous in vitro studies used bovine teeth $[45,46]$ (Figure 7). The University of Valencia Research Ethics Committee approved the study design (Registration number: 1,226,464).

The product based on $15 \% \mathrm{HCl}$, Icon Etch (DMG, Germany), was applied to the tooth in position 1.14 times at $2 \mathrm{~min}$ each, as per the manufacturer's instructions. The tooth at position 2.1 received the product based on $6.6 \% \mathrm{HCl}$ (Opalustre, Ultradent) with silicon carbide particles applied with OpalCups (Ultradent). This tooth received 4 applications at 1 min each, as per the manufacturer's instructions. 


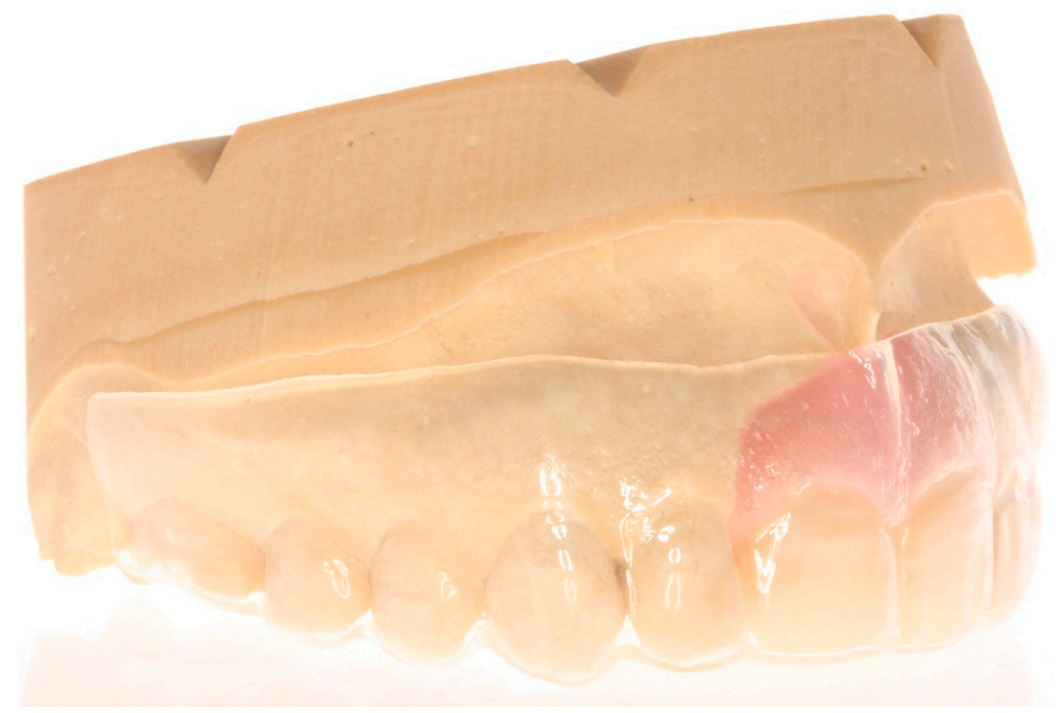

Figure 7. The master model that demonstrated the fabrication of a customized tray used as a container for applying the product; it has a perforation vestibular to the affected tooth made with a $5 \mathrm{~mm}$ diameter trephine.

The teeth were scanned with the intraoral scanner (TrueDefinition, 3M-ESPE) after each application, generating STL files used to analyze enamel volume changes by superimposing the files and using the specialized software. Specifically, we used the Geomagic Wrap (3D system), which aligned the data in each file by means of the best fit algorithm, and the GOM Inspect program (Precise Industrial 3D Metrology), which generated a gradient color map that represented variations in enamel volume changes (Figure 8).
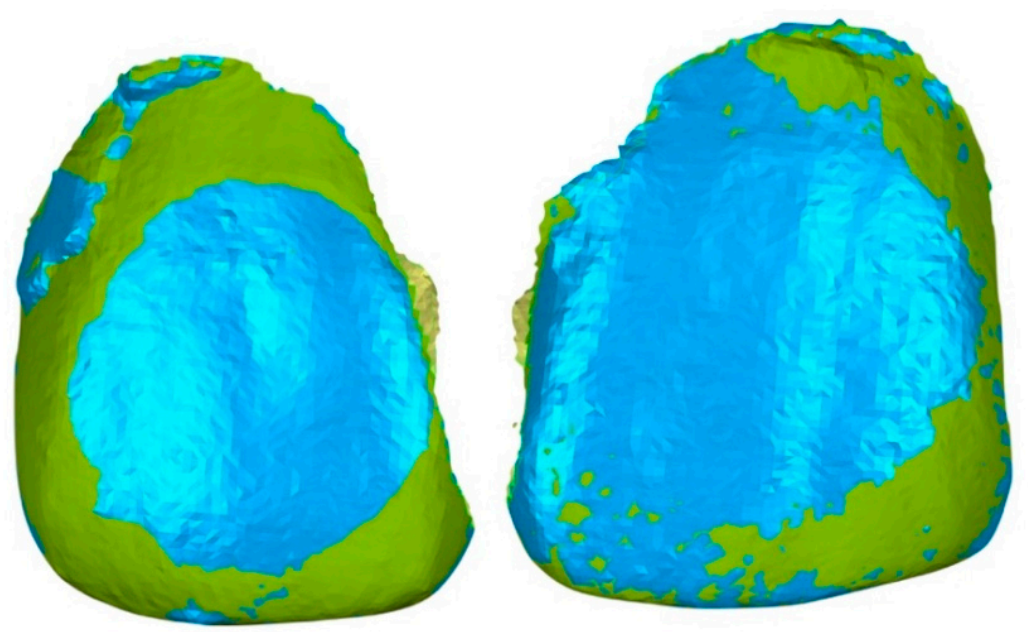

Figure 8. The superimposed STL files.

\subsection{Scanning Electron Microscopic (SEM) Analysis}

After overlapping the files, we decided to visualize the samples under a scanning electron microscope (SEM) to observe the etching pattern obtained following the application of both $\mathrm{HCl}$ products. To do this, we adhered the samples to a metal support using an adhesive strip. Once fixed, the samples were introduced into metallization equipment and following an evaporation technique, the samples were metalized with $\mathrm{Au}-\mathrm{Pd}$. The samples were then introduced into a specific attachment used to capture images under the scanning electron microscope (Carl Zeiss Ultra 55, Cambridge, U.K.). They were then observed at the following magnifications: $1000 \times, 2500 \times, 5000 \times$, and finally at 10,000x. 


\section{Results}

The superimposition process of the STL files resulted in the following:

a. In chemical erosion treatment cases, i.e., those that used 15\% $\mathrm{HCl}$ (Icon Etch; DMG), the mean volume of enamel eliminated was $-0.042 \mathrm{~mm}$ (Figure 9).

b. In cases that used the erosive abrasion treatment, i.e., those treated with $6.6 \% \mathrm{HCl}$ (Opalustre; Ultradent), the mean volume of enamel eliminated was $-0.12 \mathrm{~mm}$ (Figure 10).

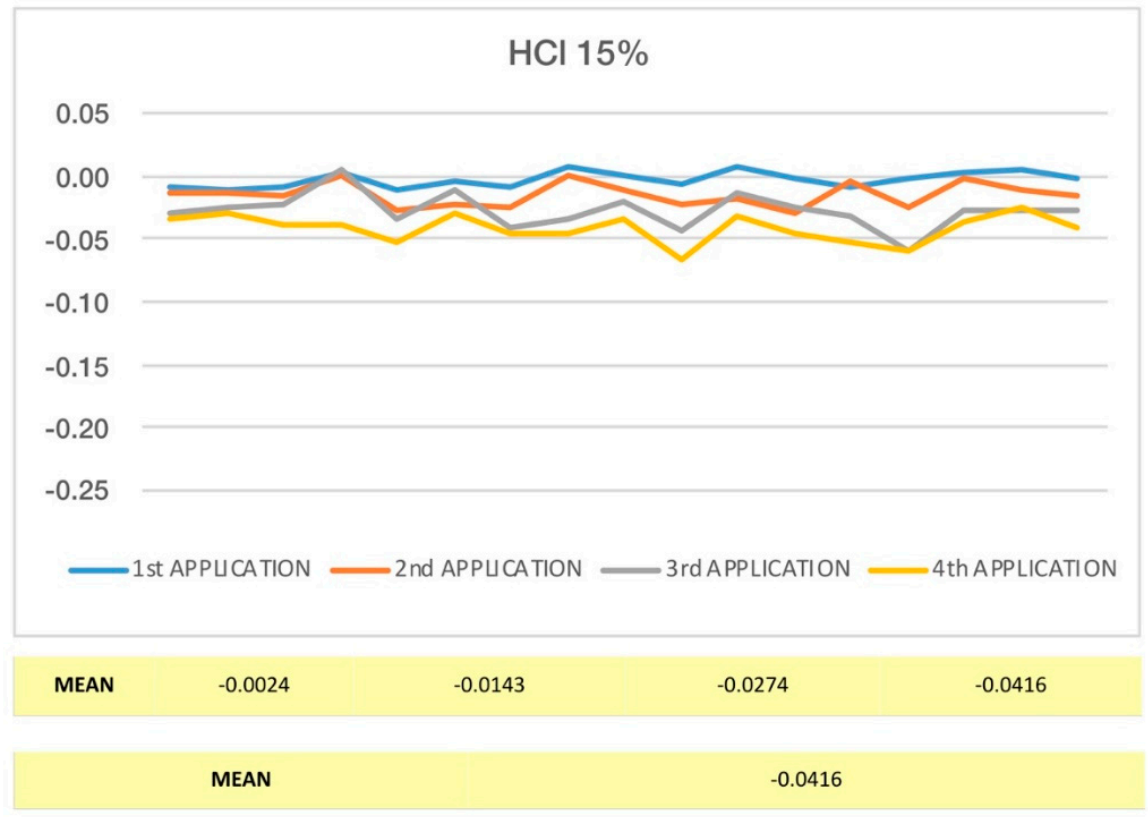

Figure 9. The mean erosion values after applying 15\% $\mathrm{HCl}$.

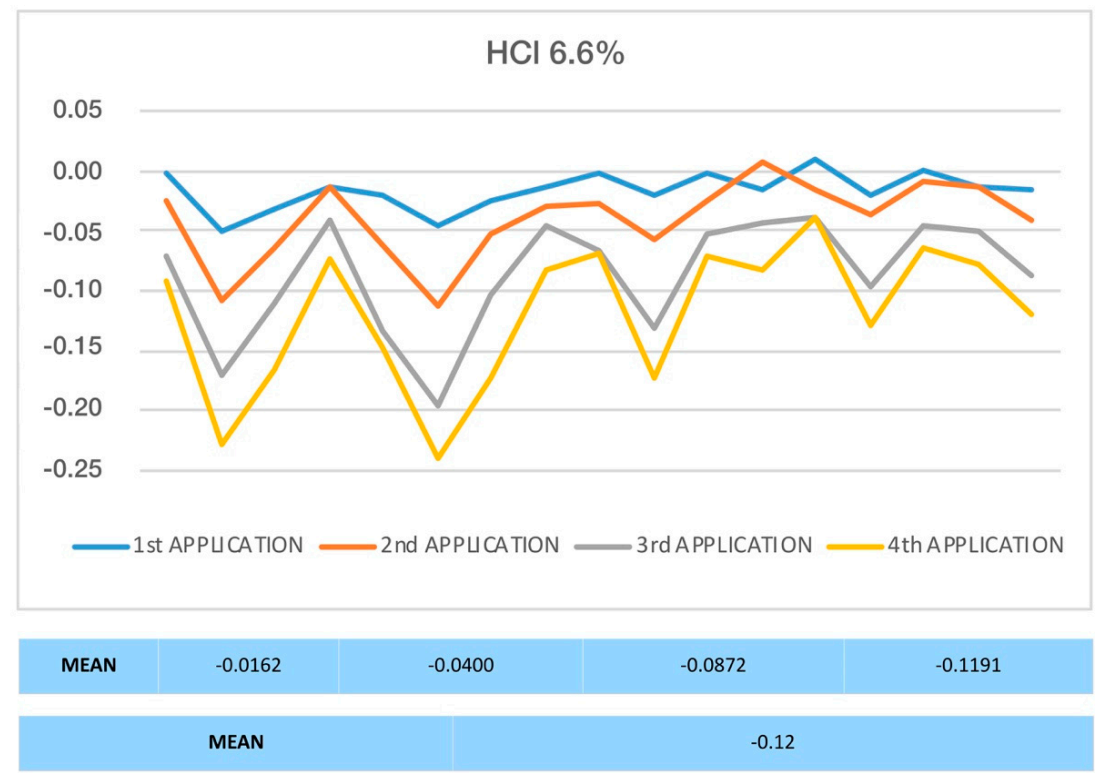

Figure 10. The mean erosion values after applying $6.6 \% \mathrm{HCl}$.

All of the results obtained were statistically analyzed; that is, the significance level used in the analysis was $5 \%(\alpha=0.05)$. To evaluate the change in enamel volume between the different applications and their initial states, a paired $t$-test was used. This test contrasts the homogeneity of the means obtained. These were the conclusions: when each application was evaluated with the initial situation 
of the untreated tooth, we observed that $6.6 \% \mathrm{HCl}$ removes more enamel than $15 \% \mathrm{HCl}$ in the first application $(P=0.002$; $t$-test $)$, in the second application $(P=0.006 ; t$-test $)$, as well as in the third and fourth applications $(P<0.001 ; t$-test $)$ in a statistically significant way.

The volume reductions were measured in comparison between the results of the different application methods, rather than between each method and their respective initial situation. We observed that in the first application, both products removed the same amount of enamel. In the second application, the $6.6 \% \mathrm{HCl}$ had a volume reduction that was not statistically significant. Finally, in the third $(P<0.001$; $t$-test $)$ and fourth $(P<0.010$; $t$-test $)$ applications of $6.6 \% \mathrm{HCl}$, statistically significant values were observed (Figures 11-16).
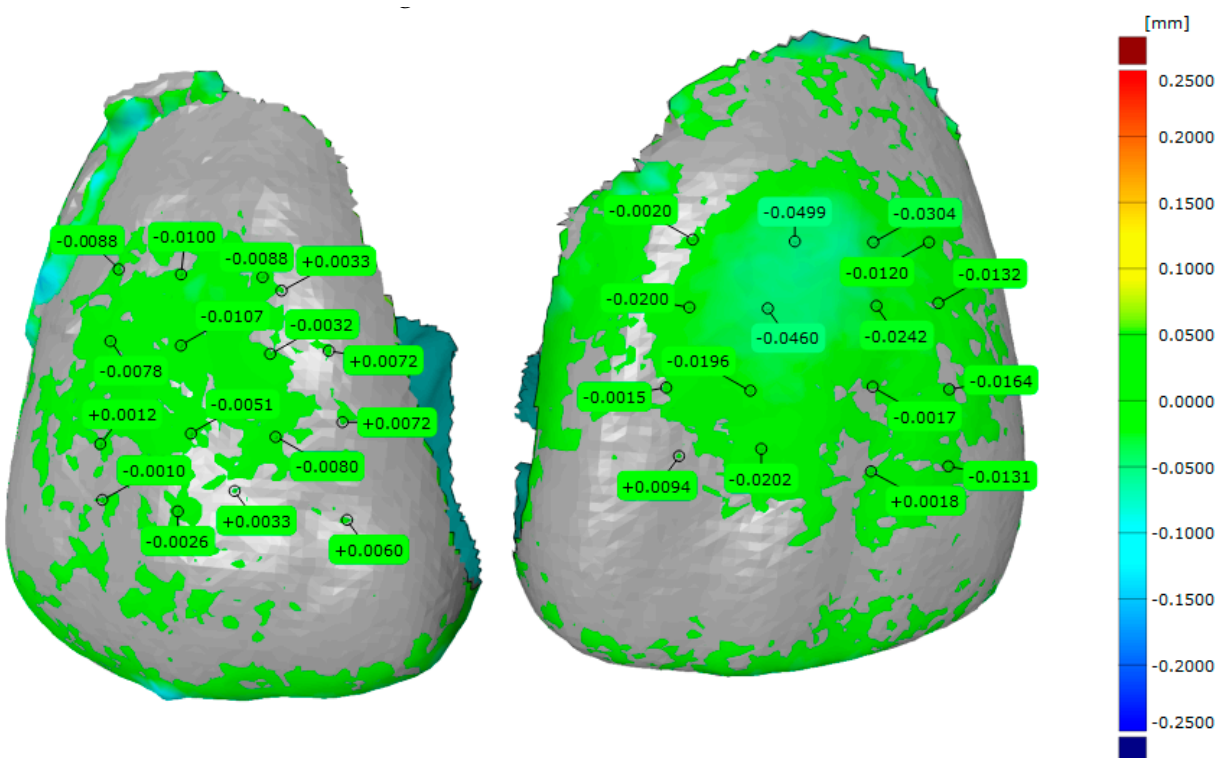

Figure 11. The mean values of the erosion in the dental surface after the first application with a gradient color map representing variations from enamel volume changes. The left tooth was treated with the $15 \% \mathrm{HCl}$ treatment and the right tooth was treated with the $6.6 \% \mathrm{HCl}$ treatment.
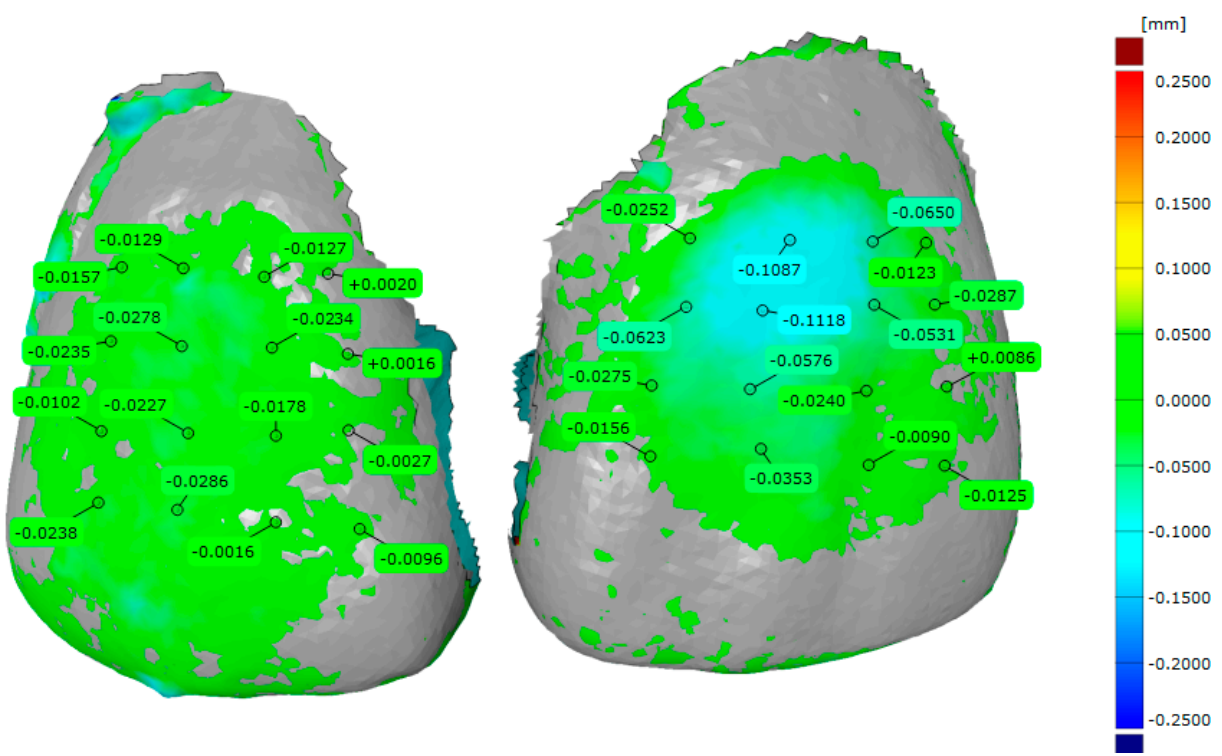

Figure 12. The mean values of the erosion in the dental surface after a second application with a gradient color map representing variations from enamel volume changes. The left tooth was treated with the $15 \% \mathrm{HCl}$ treatment and the right tooth was treated with the $6.6 \% \mathrm{HCl}$ treatment. 

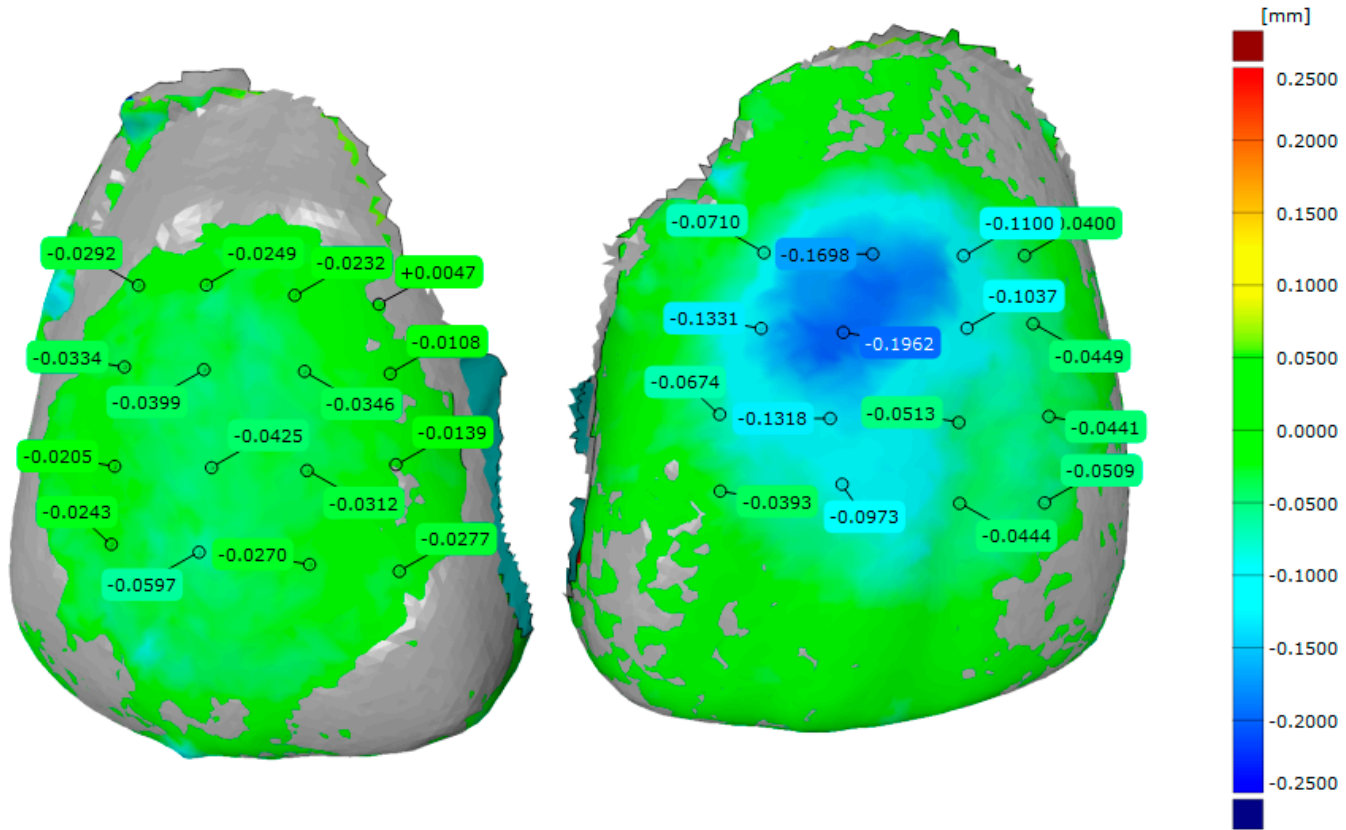

Figure 13. The mean values of the erosion in the dental surface after the third application with a gradient color map representing variations from enamel volume changes. The left tooth was treated with the $15 \% \mathrm{HCl}$ treatment and the right tooth was treated with the $6.6 \% \mathrm{HCl}$ treatment.
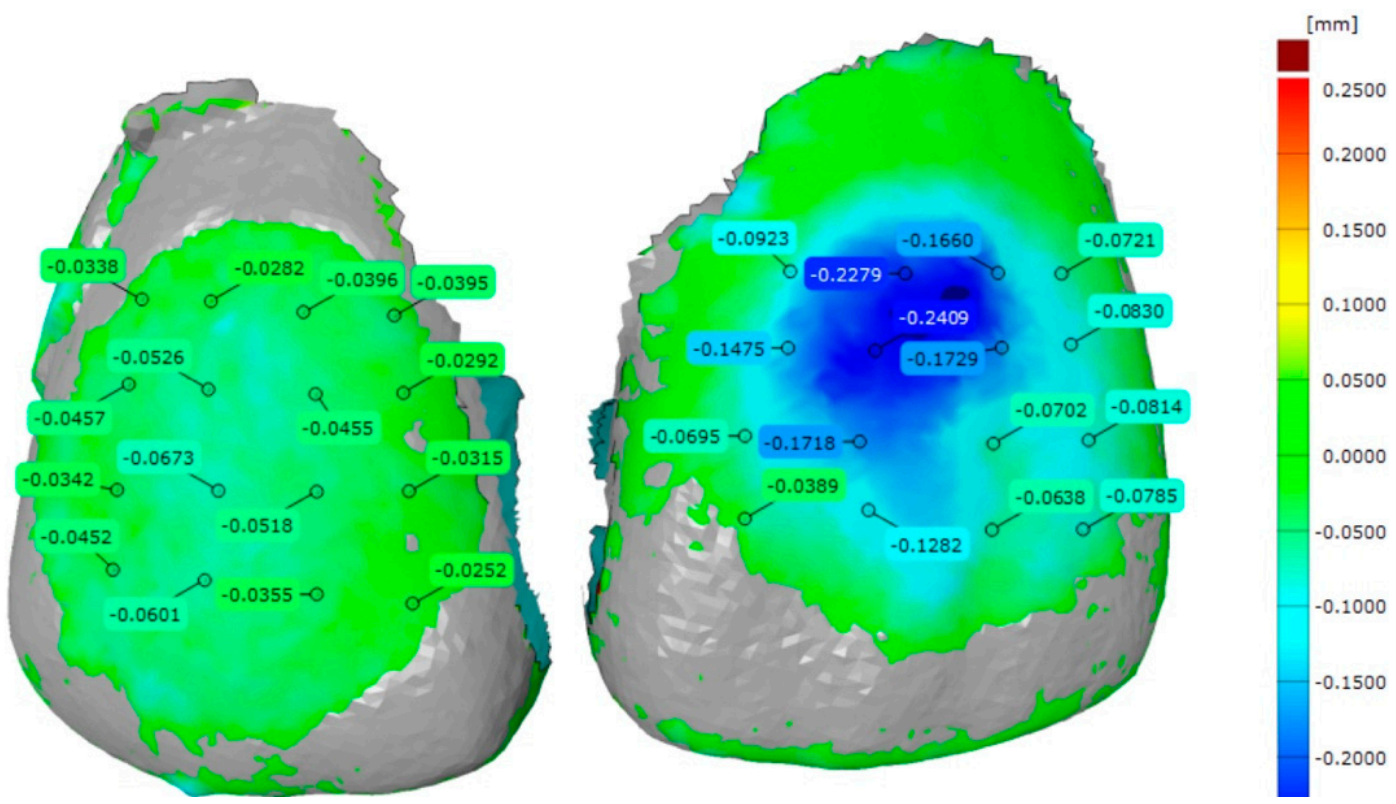

Figure 14. The mean values of the erosion in the dental surface after the fourth application with a gradient color map representing variations from enamel volume changes. The left tooth was treated with the $15 \% \mathrm{HCl}$ treatment and the right tooth was treated with the $6.6 \% \mathrm{HCl}$ treatment. 


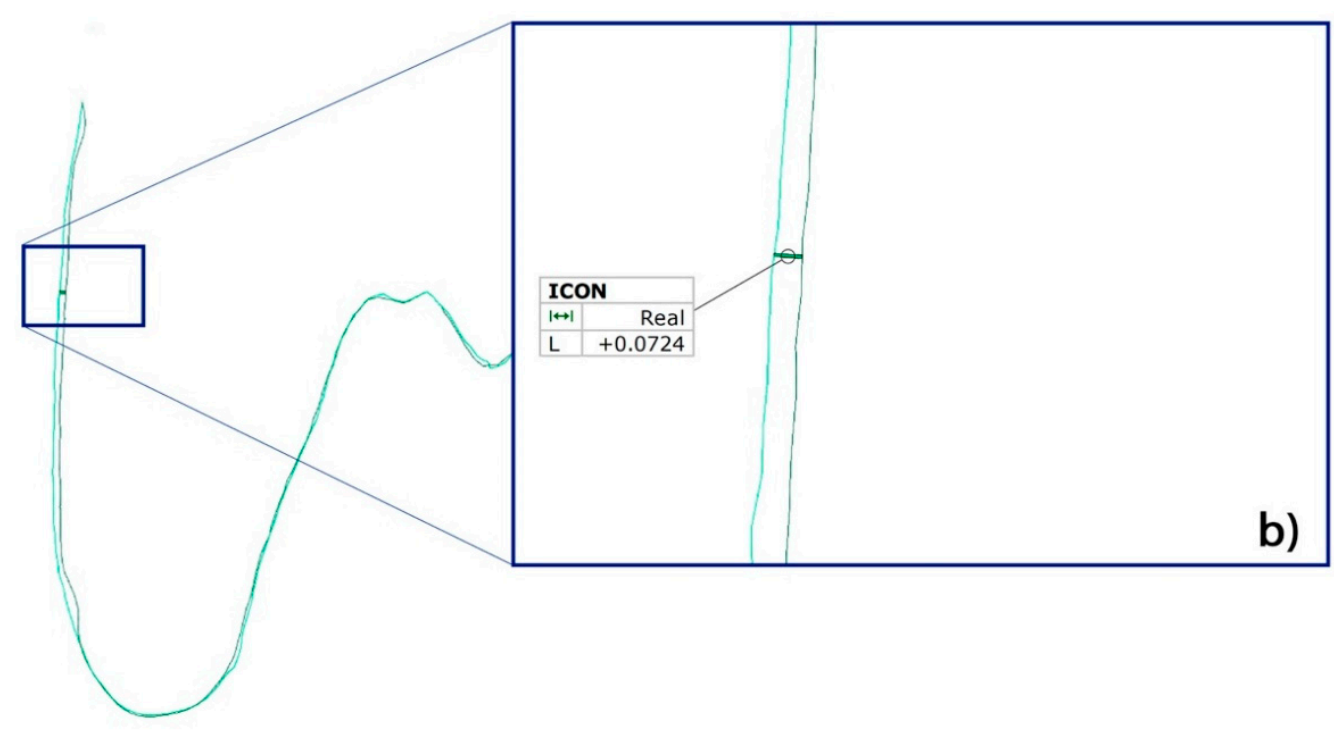

a)

Figure 15. A digital volumetric analysis in a sagittal plane. (a) The volumetric change in the dental vestibular area after applying $15 \% \mathrm{HCl}$. (b) The volume reduction in the vestibular area with the greater convexity of the treated tooth.

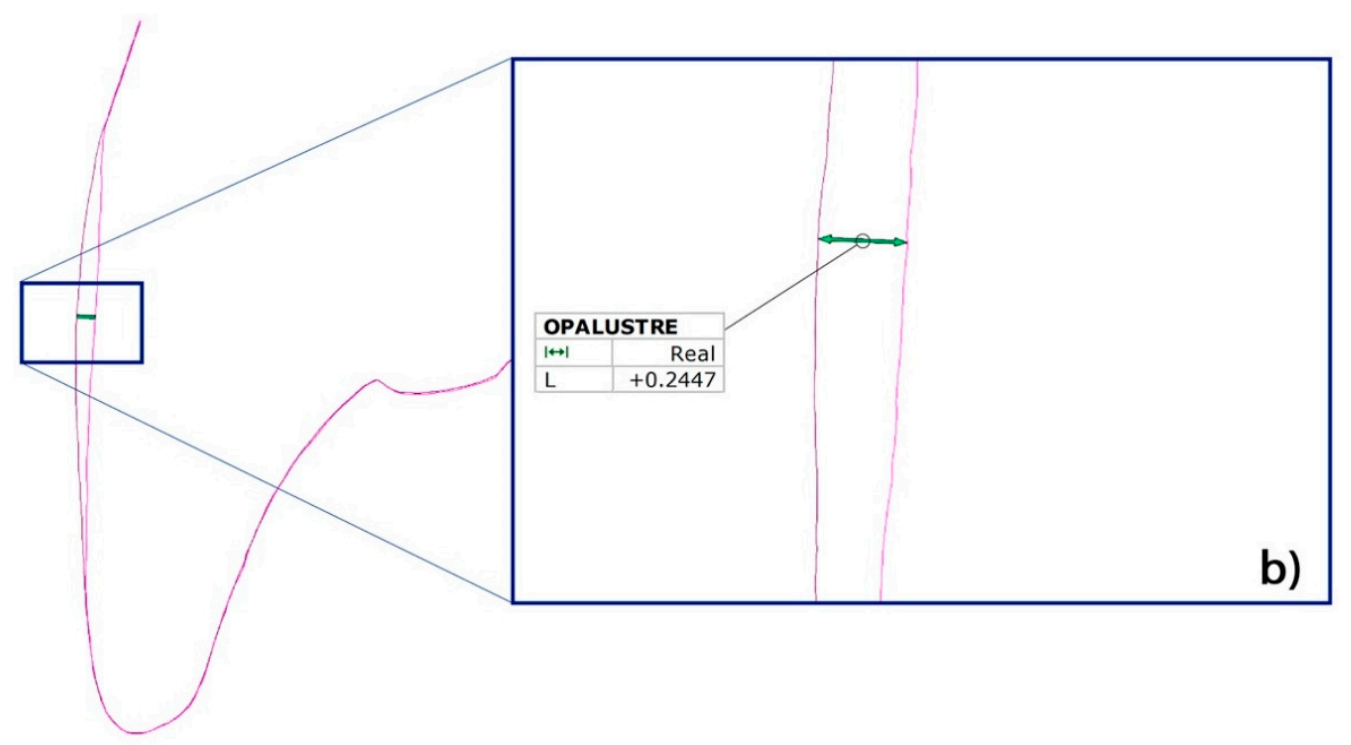

\section{a)}

Figure 16. A digital volumetric analysis in a sagittal plane. (a) The volumetric change of the dental vestibular area after the application of $6.6 \% \mathrm{HCl}$. (b) The volume reduction in the vestibular area with the largest contour of the treated tooth.

\section{Discussion}

The techniques for eliminating white spots by means of HCl-based products described above may represent an alternative or coadjuvant treatment to the more commonly used techniques such as remineralization or restoration with resin composite.

Hydrochloric acid at different concentrations has been used in esthetic dentistry for eliminating enamel marks since 1916, when Walter Kane used 36\% HCl and heat to remove fluorosis stains. Due to the high concentration, the technique produced satisfactory results, but given the risk of destroying 
the enamel, reports of the treatment were not published. In 1941, Raper was the first to describe the technique of fluorosis stain removal, who did so using $\mathrm{HCl}$ at a lower concentration than used by Kane to ensure safety; $18 \% \mathrm{HCl}$ was applied with a cotton wool swab, was left on the enamel for $10 \mathrm{~min}$, and was followed by an application of sodium bicarbonate to neutralize the effect of the acid [37]. In 1989, a micro-abrasion technique was described by Croll that involved using a solution that combined chemical erosion with $18 \% \mathrm{HCl}$ and mechanical abrasion using a pumice stone, thus eliminating the surface layer of the enamel and the white spots within it [38]. This practice is still considered a safe, effective, and atraumatic technique for eliminating enamel defects derived from hypomineralization or minimal hypoplasia.

An alternative to microabrasion is enamel infiltration with a low-viscosity photopolymerizable resin [30]. This involves pretreating the spot and completely eroding the enamel's impermeable surface layer to expose the lesion before resin infiltration. The surface layer can be removed mechanically with a bur or disc [39], but this generates a smear layer that obstructs the prisms making subsequent infiltration difficult. A better option is to remove the surface layer by means of acid etching, which allows controlling the reduction of the surface layer and leave the tubules open for later infiltration. The available literature on this topic includes several articles that aimed to compare the erosive capacity of various acids including orthophosphoric acid at $37 \%$ and $\mathrm{HCl}$ at various concentrations for eliminating the enamel surface layer.

Different studies by Meyer-Lueckel et al. stated that enamel discoloration can only be eliminated by products based on $15 \% \mathrm{HCl}$ due to its capacity to etch the tooth surface more effectively than orthophosphoric acid, although the latter is still used in regular practices [31,40]. Yim reported that the enamel surface etching capacity of $\mathrm{HCl}$ was 2.7 times greater than orthophosphoric acid and noted that the etching patterns also differed [41].

On the basis of the greater capacity of $\mathrm{HCl}$ to erode the tooth enamel surface $[31,40,41]$, the present study's intentions were to conduct an in vitro comparison of two $\mathrm{HCl}$-based products with concentrations of $6.6 \%$ and $15 \%$. Our aim was to investigate the influence of the concentration and the application time of these products upon the enamel surface. Previous studies have yet to provide a clear report of the quantity of enamel eliminated by the $\mathrm{HCl}$ products with each application [42-46].

An in vitro study by Arnold et al. evaluated the erosive capacity of a $15 \% \mathrm{HCl}$ solution by means of optical profilometry, reporting that treatment with $15 \% \mathrm{HCl}$ will erode dental enamel to a greater or lesser degree depending on the application time. The present study obtained similar results, though with lower erosion values than Arnold et al. We found that $\mathrm{HCl}$ rapidly destroys the crystalline structure of hydroxyapatite, and repeated applications increase the extent of destruction. For this reason, caution must be used to protect the areas adjacent to the lesion. In the present work, trays were fabricated as containers for the product, which protected the area surrounding the lesion against damage to the enamel structure [47].

Román Rodríguez et al. published a clinical case report that stated they eliminated enamel surface lesions using a $6.6 \% \mathrm{HCl}$ paste containing silicon carbide particles, thus obtaining erosion values similar to the present study [16].

We used STL files to superimpose and evaluate the amount of erosion produced by the two products tested. The data were processed with image superimposition software to enable a comparative analysis between different STL files with the method known as the best fit algorithm. This superimposition software offers several advantages to both dentists and researchers who need to analyze data quickly and efficiently and compare volumetric changes produced in different oral structures after clinical treatment. This method has been described as an adequate tool for evaluating volume changes in both dental [16] and gingival [48] tissue.

According to our study's findings, both $\mathrm{HCl}$-based products tested are apt for treating white spots, as they are both capable of producing enamel demineralization without reaching dentine. The $15 \%$ $\mathrm{HCl}$ used in the chemical erosion technique caused less erosion of the enamel's surface but did so 
uniformly, whereas the abrasive erosion technique with $6.6 \% \mathrm{HCl}$ and OpalCups produced twice the amount of erosion in the surface enamel and in a shorter application time.

As in other studies $[41,46,47,49]$, both teeth were analyzed under an electronic microscope in order to examine the surface characteristics produced by the chemical erosion and abrasive erosion processes. We observed that the tooth treated with chemical erosion presented an etching pattern with complete erosion at the centers of the enamel prisms. These enamel prisms retained prominent edges (Figure 17), indicating that the surface produced was adequate for subsequent adhesive and infiltration procedures. On the tooth treated with the abrasive erosion technique, the surface underwent heterogeneous abrasion on which a surface layer persisted without any type of etching pattern that would allow the infiltration by any type of resin (Figure 18).

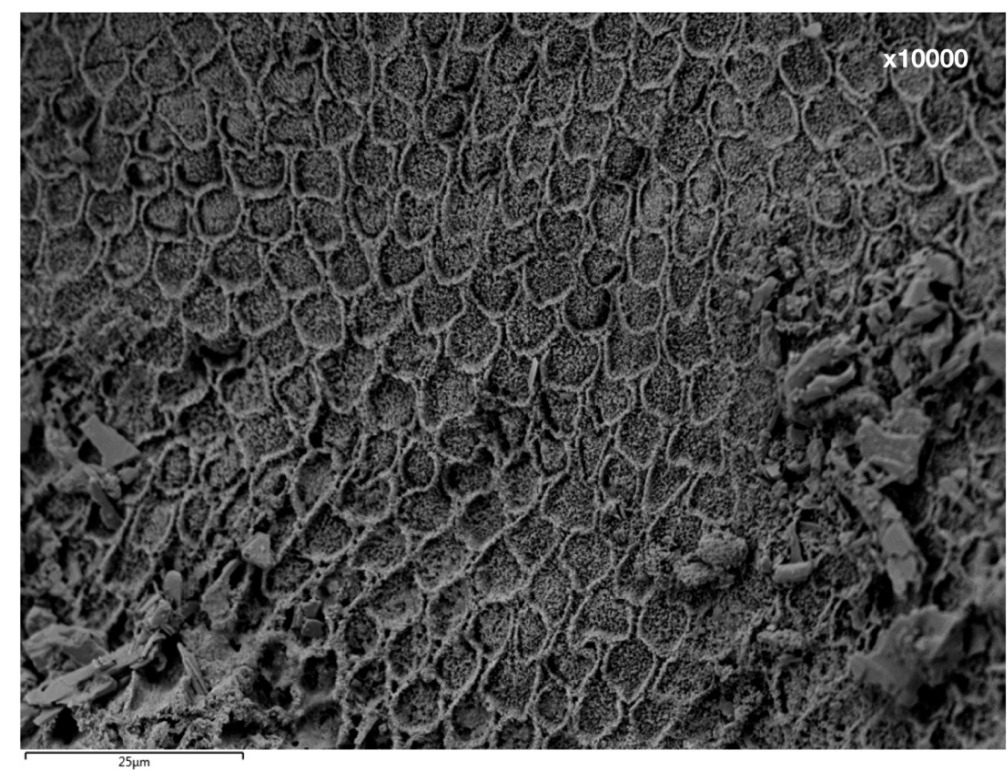

Figure 17. The etching pattern of the enamel surface after the $15 \% \mathrm{HCl}$ application (chemical erosion technique).

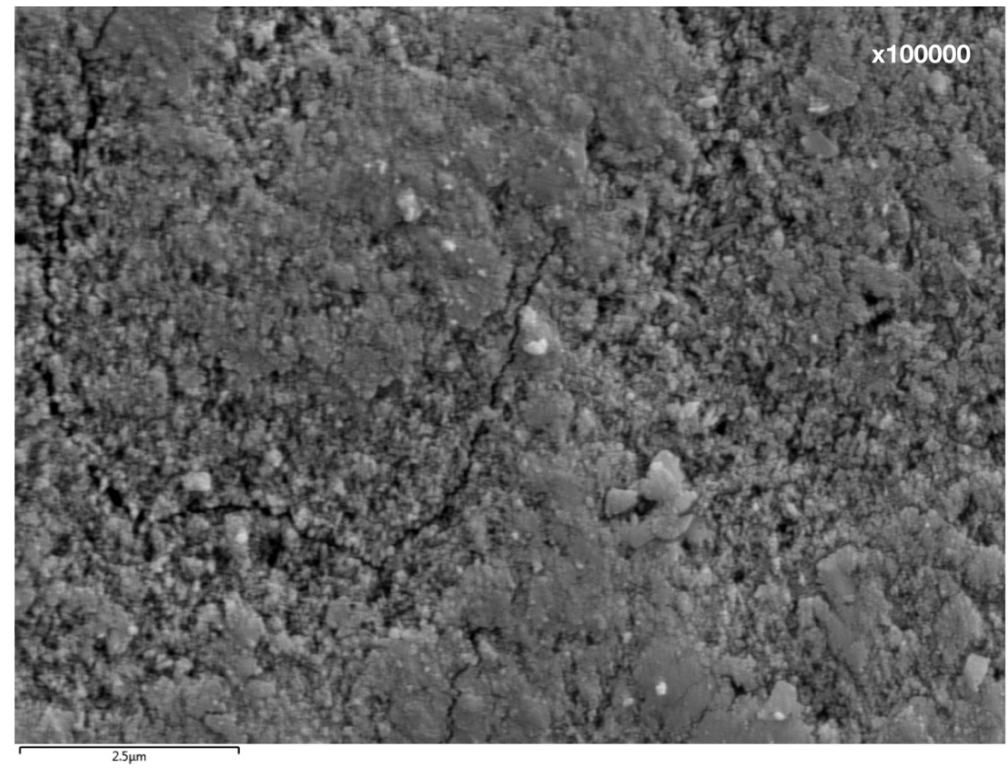

Figure 18. The etching pattern of the enamel surface after the $6.6 \% \mathrm{HCl}$ application with OpalCups (abrasive erosion technique). 
For this reason, although the $6.6 \% \mathrm{HCl}$ application has a greater erosive potential according to the data obtained in our study, we must use it clinically to remove superficial stains that do not require a subsequent adhesive procedure, since the surface it leaves is unsuitable for adhesive procedures and restorers. The $15 \% \mathrm{HCl}$ application will be used to both remove superficial stains and spots in a minimally invasive way as well as to remove and/or camouflage deeper stains along with adhesive and macroabrasion techniques.

\section{Conclusions}

In this study, we showed that both $\mathrm{HCl}$-based products (at $6.6 \%$ or $15 \% \mathrm{HCl}$ ) are adequate options for treating white spot lesions. In both cases, the engraving depth does not exceed the thickness of the enamel layer. The depth of the etched surface layer was dependent upon the etching time and the application mode. Furthermore, the depth of the etched surface layer could be monitored via a digital volumetric analysis to avoid destroying the entire enamel layer, which would impair the prognosis for adhesion and subsequent restoration. The long-term effects of $6.6 \%$ and $15 \% \mathrm{HCl}$ etching products should be followed up with continuous clinical and scientific research.

Author Contributions: All of the authors contributed to the investigation, supervision, writing, review, and editing of the study. Study conceptualization was carried out by A.R.-V., M.F.S.-R., and R.A.-P. Data curation, data visualization, and analysis were performed by J.A.P.-B., J.A.-L., and J.L.R.-R. All authors have read and agreed to the published version of the manuscript.

Funding: This research received no external funding.

Acknowledgments: The authors would like to express their thanks to Alberto Alvarez García-Pumarino, Digital Dentistry Global Scientific Affairs Manager at 3M Oral Care, for his advice, guidance, and help in creating and managing STL files.

Conflicts of Interest: This manuscript has not been published and is not under consideration for publication elsewhere. We have no conflict of interest to disclose and all authors have approved the manuscript and agreed to its submission.

\section{References}

1. Nanci, A. Enamel: Composition, formation, and structure. In Ten Cate's oral Histology Development, Structure, and Function; Nanci, A., Ed.; Mosby Elsevier: St. Louis, MO, USA, 2008; pp. 141-190.

2. Freiman, A.; Borsuk, D.; Barankin, B.; Sperber, G.H.; Krafchik, B. Dental manifestations of dermatologic conditions. J. Am. Acad. Dermatol. 2009, 60, 289-298. [CrossRef] [PubMed]

3. Seow, W.K. Enamel hipoplasia in the primary dentition: A review. J. Dent. Child. 1991, 58, 441-452.

4. Seow, W.K. Developmental defects of enamel and dentine: Challenges for basic science research and clinical management. Aust. Dental. J. 2014, 59, 143-154. [CrossRef] [PubMed]

5. Fernandez, L.; Vicente, M.; García, V.; Montiel, J.M.; Paredes, V.; Almerich, J.M.; Bellot, C. Enamel remineralization therapies for treating post orthodontic white-spot lesions. J. Am. Dent. Assoc. 2018, 149, 778-786. [CrossRef]

6. $\quad$ Freitas, M.C.C.A.; Nunes, L.V.; Comar, L.P.; Rios, D.; Magalhaes, A.C.; Honório, H.M.; Wang, L. In vitro effect of a resin infiltrant on different artificial caries-like enamel. Arch. Oral Biol. 2018, 95, 118-124. [CrossRef]

7. Denis, M.; Atlan, A.; Vennat, E.; Tirlet, G.; Attal, J.P. White defects on enamel: Diagnosis and anatomopathology: Two essential factors for proper treatment (part 1). Int. Orthod. 2013, 11, 139-165. [CrossRef]

8. $\quad$ Borges, A.B.; Caneppele, T.M.F.; Materson, D.; Maia, L.C. Is resin infiltration an effective esthetic treatment for enamel development defects and White spot lesions? A systematic review. J. Dent. 2017, 56, 11-18. [CrossRef]

9. Mazur, M.; Westland, S.; Guerra, F.; Corridore, D.; Vichi, M.; Maurotti, A. Objective and subjective aesthetic performance of Icon treatment for enamel hypomineralization lesions in young adolescents: A retrospective single center study. J. Dent. 2018, 68, 104-108. [CrossRef]

10. Castiblanco, G.A.; Martignon, S.; Castellanos, J.E.; Mejía, W.A. Pathogenesis of dental fluorosis: Biochemical and cellular. Rev. Fac. Odontol. Univ. Antioq. 2017, 28, 408-421. [CrossRef] 
11. Weerheijm, K.L.; Jälevikb, B.; Alaluusua, S. Molar incisor-hypomineralisation. Caries. Res. 2001, 35, 390-391. [CrossRef]

12. Gorelick, L.; Geiger, A.M.; Gwinett, A.J. Incidence of White spot formation after bonding and banding. Am. J. Orthod. 1982, 81, 93-98. [CrossRef]

13. Hadler-Olsen, S.; Sandvik, K.; El-Agroudi, M.A.; Øgaard, B. The incidence of caries and white spot lesions in orthodontically treated adolescents with a comprehensive caries prophylactic regimen-A prospective study. Eur. J. Orthod. 2011, 34, 633-639. [CrossRef] [PubMed]

14. Boersma, J.G.; Van der Veen, M.H.; Lagerweij, M.D.; Bokhout, B.; Prahl-Andresen, B. Caries prevalence measured with QLF after treatment with fixed orthodontic appliances: Influencing factors. Caries Res. 2005, 39, 41-47. [CrossRef]

15. Eltayeb, M.K.; Ibrahim, I.E.; El Karim, I.A.; Sanhouri, N.M. Distribution of white spot lesions among orthodontic patients attending teaching institutes in Khartoum. BMC Oral. Health. 2017, 17, 88. [CrossRef] [PubMed]

16. Paula, A.B.; Fernandes, A.R.; Coelho, A.S.; Marto, C.M.; Ferreira, M.M.; Caramelo, F.; do Vale, F.; Carrilho, E. Therapies for White Spot Lesions-A Systematic Review. J. Evid. Based Dent. Pract. 2017, 17, $23-38$. [CrossRef]

17. Román-Rodríguez, J.L.; Agustín-Panadero, R.; Roig-Vanaclocha, A.; Amengual-Lorenzo, J. A tooth whitening and chemical abrasive protocol for the treatment of developmental enamel defects. J. Prosthet. Dent. 2020, 123, 379-383. [CrossRef] [PubMed]

18. Knösel, M.; Attin, R.; Beckers, K.; Attin, T. A randomized CIE L*a*b* evaluation of external bleaching therapy effects on fluorotic enamel stains. Quint. Int. 2008, 39, 391-399.

19. Bailey, D.L.; Adams, G.G.; Tsao, C.E.; Hyslop, A.; Escobar, K.; Manton, D.J. Regression of post-orthodontic lesions by a remineralizing cream. J. Dent. Res. 2009, 88, 1148-1153. [CrossRef]

20. Willmot, D.R. White lesions after orthodontic treatment: Does low fluoride make a difference? J. Orthod. 2004, 31, 235-242. [CrossRef]

21. Cate, J.M.; Arends, J. Remineralization of artificial enamel lesions in vitro. Caries Res. 1977, 12, $277-286$. [CrossRef]

22. Naumova, E.A.; Niemann, N.; Aretz, L.; Arnold, W.H. Effects of different amine fluoride concentrations on enamel remineralization. J. Dent. 2012, 40, 750-755. [CrossRef] [PubMed]

23. Van der Veen, M.H.; Mattousch, T.; Boersma, J.G. Longitudinal development of caries lesions after orthodontic treatment evaluated by quantitative light-induced fluorescence. Am. J. Orthod. Dentofacial. Orthop. 2007, 131, 223-228. [CrossRef] [PubMed]

24. Ardu, S.; Castioni, N.V.; Benbachir, N.; Krehci, I. Minimally invasive treatment of white spot enamel lesions. Quint. Int. 2007, 38, 633-636.

25. Øgaard, B. Incidence of filled surfaces from 10 to 18 years of age in an orthodontically treated and untreated group in Norway. Eur. J. Orthod. 1989, 11, 116-119. [CrossRef]

26. Benbachir, N.; Ardu, S.; Krejci, I. Indications and limits of the microabrasion technique. Quint. Int. 2007, 38, 811-815.

27. Croll, T.P. Enamel microabrasion: The technique. Quint. Int. 1989, 20, 395-400.

28. Croll, T.P.; Helpin, M.L. Enamel microabrasion: A new approach. J. Esthet. Dent. 2000, 12, 64-71. [CrossRef]

29. Sundfeld, R.H.; Croll, T.P.; Briso, A.L.; de Alexandre, R.S.; Sundfeld-Neto, D. Considerations about enamel microabrasion after 18 years. Am. J. Dent. 2007, 20, 67-72.

30. Raper, H.R.; Manser, J.G. Removal of brown stains from fluorine mottled teeth. Dent. Digit. 1941, 9, 390-396.

31. Ardu, S.; Benbachir, N.; Stavridakis, M.; Dietschi, D.; Krejci, I.; Feilzer, A. A combined chemo-mechanical approach for aesthetic management of superficial enamel defects. Br. Dent. J. 2009, 206, 205-208. [CrossRef]

32. Croll, T.P. Bonded resin selant for smooth surface enamel defects: New concepts in microrestorative dentistry. Quint. Int. 1987, 18, 5-10.

33. Paris, S.; Meyer-Lueckel, H.; Kielbassa, A.M. Resin infiltration of natural caries lesions. J. Dent. Res. 2007, 7, 662-666. [CrossRef] [PubMed]

34. Paris, S.; Meyer-Lueckel, H. Masking of labial enamel white spot lesions by resin infiltration- a clinical report. Quint. Int. 2009, 40, 713-718.

35. Paris, S.; Dorfer, C.E.; Meyer-Lueckel, H. Surface conditioning of natural enamel caries lesions in deciduous teeth in preparation for resin infiltration. J. Dent. 2010, 38, 65-71. [CrossRef] 
36. Tirlet, G.; Chabouis, H.F.; Attal, J.P. Infiltration, a new therapy for masking enamel White spots: A 19-month follow-up case series. J. Esthet. Dent. 2013, 8, 180-190.

37. Cazzolla, A.P.; De Franco, A.R.; Lacaita, M.; Lacarbonara, V. Efficacy of 4-year treatment of icon infiltration resinon postorthodontic white spot lesions. BMJ Case Rep. 2018. [CrossRef]

38. Atsu, S.S.; Aka, P.; Cenker, H.; Atakan, C. Age-related changes in tooth enamel as measured by electron microscopy: Implications for porcelain laminate veneers. J. Prosthet. Dent. 2005, 94, 336-341. [CrossRef]

39. Sanmarco, G. Combined minimally invasive treatment of White and brown fluorotic discolorations in a teenager: A case report. Int. J. Esthet. Dent. 2019, 14, 148-155.

40. Burke, F.J.; Kelleher, M.G. The "daughter test" in elective esthetic dentistry. J. Esthet. Restor. Dent. 2009, 21, 143-146. [CrossRef]

41. Yim, H.K.; Kwon, H.K.; Kim, B.I. Modification of surface pre-treatment for resin infiltration to mask natural white spot lesions. J. Dent. 2014, 42, 588-594. [CrossRef]

42. Meyer-Lueckel, H.; Paris, S.; Kielbassa, A.M. Surface layer erosion of natural caries lesions with phosphoric and hydrochloric acid gels in preparation for resin infiltration. Caries. Res. 2007, 41, 223-230. [CrossRef] [PubMed]

43. Balmer, R.C.; Laskey, D.; Mahoney, E.; Toumba, K.J. Prevalence of enamel defects and MIH in non-fluoridates and fluoridated communities. Eur. J. Paediatr. Dent. 2005, 6, 209-212. [PubMed]

44. Robles, M.J.; Ruiz, M.; Bravo-Perez, M.; González, E.; Peñalver, M.A. Prevalence of enamel defects in primary and permanent teeth in a group of school children from Granada (Spain). Med. Oral. Patol. Oral. Cir. Bucal. 2013, 18, 187-193. [CrossRef] [PubMed]

45. Paris, S.; Schwendicke, F.; Keltsch, J.; Dörfer, C.; Meyer-Lueckel, H. Masking of white spot lesions by resin infiltration in vitro. J. Dent. 2013, 41, 28-34. [CrossRef] [PubMed]

46. Yim, H.K.; Min, J.H.; Kwon, H.K.; Kim, B.I. Modification of surface pretreatment of white spot lesions to improve the safety and efficacy of resin infiltration. Korean J. Orthod. 2014, 44, 195-202. [CrossRef]

47. Arnold, W.H.; Haddad, B.; Schaper, K.; Hagemann, K.; Lippold, C.; Danesh, G. Enamel surface alterations after repeated conditioning with HCL. Head Face Med. 2015, 11, 32. [CrossRef]

48. Fons-Badal, C.; Pérez-Barquero, J.A.; Martínez-Martínez, N.; Faus-López, J.; Fons-Font, A.; Agustín-Panadero, R. A novel, fully digital approach to quantifying volume gain after soft tissue graft surgery. A pilot study. J. Clin. Periodontol. 2019, 20, 614-620. [CrossRef]

49. Mohamed, A.M.; Wong, K.H.; Lee, W.J.; Marizan Nor, M.; Mohd Hussaini, H.; Rosli, T.I. In vitro study of white spot lesion: Maxilla and mandibular teeth. Saudi. Dent. J. 2018, 30, 142-150. [CrossRef] 